\title{
Electric Air Conditioning Control Method of Electric Bus Based on Driving Conditions
}

\author{
Yong $\mathrm{LUO}^{1, \mathrm{a}}$, Li-fu $\mathrm{LI}^{2}$ and Yan-ping TAN ${ }^{1}$ \\ ${ }^{1}$ College of Computer and Information Engineering, Guizhou University of Commerce, Guiyang 550004, China \\ ${ }^{2}$ School of Mechanical and Automotive Engineering, South China University of Technology, Guangzhou 510640, China
}

\begin{abstract}
For reducing energy consumption of electric air conditioning $(\mathrm{E}-\mathrm{A} / \mathrm{C})$ in electric bus, an E-A/C control method based on driving conditions (including the temperature of bus compartment, the number of passengers, the state of charge (SOC) of battery) is proposed. Firstly, the relationship between E-A/C cooling load and driving conditions is theoretically researched, then an E-A/C control method by dynamically adjusting compartment temperature is proposed. Secondly, an E-A/C model and a bus model are established and simulated in AVL Cruise and MATLAB, the results indicate that the proposed control method can reduce the energy consumption of E-A/C significantly, and effectively improve electric bus performance.
\end{abstract}

\section{Introduction}

Electric bus is the future of public transportation, however, driving range hinders the promotion of electric bus. As the system for ensuring the comfort of bus compartment, the work status of $\mathrm{E}-\mathrm{A} / \mathrm{C}$ can make big difference to bus performance ${ }^{[1]}$. For example, due to the use of E-A/C, the economy of bus decreased by $42.9 \%$, driving range decreased by $33.9 \%{ }^{[2]}$ in summer Beijing city cycle. How to reduce the energy consumption of E$\mathrm{A} / \mathrm{C}$ must be an effective way to improve electric bus performance, for this issue, Pethaiah ${ }^{[3]}$ proposed a way to add a power-supply device for E-A/C to reduce energy consumption from battery. Chien-Chin $\mathrm{CHIU}^{[4]}$ suggested to optimize heat conducting model for saving E-A/C energy. Most researchers are concentrating on the precision of $\mathrm{E}-\mathrm{A} / \mathrm{C}$ model, but neglecting the relationship between $\mathrm{E}-\mathrm{A} / \mathrm{C}$ status and electric bus driving conditions, also neglecting the dynamic characteristics of driving conditions. In this paper, dynamical bus compartment temperature is adjusted according to the changes of bus driving conditions for saving E-A/C energy, improving electric bus driving range and economy.

\section{Control principle of E-A/C based on bus driving conditions}

\subsection{E-A/C cooling load}

In summer, the energy consumption of $\mathrm{E}-\mathrm{A} / \mathrm{C}$ is mainly determined to cooling load, which can sustain bus compartment comfort. Referring to E-A/C work principle $^{[5]}, \mathrm{E}-\mathrm{A} / \mathrm{C}$ cooling load is determined to heat load received by compartment. The heat load of compartment at time $t$ can be expressed as below.

$$
\begin{aligned}
Q(t)= & Q_{B}(t)+Q_{G}(t)+Q_{P}(t)+Q_{A}(t)+Q_{s}(t) \\
= & \sum K_{b i} F_{b i}\left(T_{b i}(t)-T_{i}(t)\right)+\sum q_{g i}(t) F_{g i} \\
& +n(t) \beta Q_{n}+m_{a} C_{p}\left(T_{0}(t)-T_{i}(t)\right)+Q_{s}(t) \\
= & f\left(T_{0}(t), T_{i}(t), n(t)\right)
\end{aligned}
$$

$Q_{B}(t)=$ Heat through bus body envelope. $Q_{G}(t)=$ Heat through bus window glasses. $Q_{P}(t)=$ Heat from passengers. $Q_{A}(t)=$ Heat from outside air. $Q_{S}(t)=$ Heat from other equipment. $K_{b i}, F_{b i}, T_{b i}(t)=$ Heat transfer coefficients, heat-transfer area, surface temperature. $F_{g i}=$ Windows area. $q_{g i}(t)=$ Heat from unit window area. $T_{o}(t)=$ Outside temperature. $T_{i}(t)=$ Bus compartment temperature. $n(t)=$ Number of passengers. $\beta=$ Coefficient of aggregation. $C_{p}=$ Air specific heat capacity. $Q_{n}=$ Heat from single occupant. $m_{a}=$ Air mount from outside to compartment. $f=$ Functional relationship.

If we treat the heat of bus compartment as disturbance, then the E-A/C cooling load $Q_{L}(t)$ can be calculated by the transfer function of compartment.

$$
Q_{L}(s)=G(s) Q(s)
$$

\footnotetext{
${ }^{*}$ Corresponding author: ${ }^{a}$ luooyoong@163.com
} 
$Q_{L}(s)=$ Laplace transform of E-A/C cooling load. $Q(s)=$ Laplace transform of compartment heat. $G(s)=$ Transfer function of compartment.

To do z-transform for Eq. 2, then the transfer function of compartment as the ratio of the high-order polynomial of $z$ can be expressed as below.

$$
\begin{gathered}
Q_{L}(z)=G(z) Q(z) \\
G(z)=\frac{V_{0}+V_{1} z^{-1}+V_{2} z^{-2}+\cdots+V_{n} z^{-n}}{W_{0}+W_{1} z^{-1}+W_{2} z^{-2}+\cdots+W_{n} z^{-n}}
\end{gathered}
$$

$Q_{L}(z)=Z$-transform of cooling load. $Q(z)=Z$ transform of compartment heat. $G(z)=Z$ transfer function of compartment. $v_{j}$ and $w_{j}(j=0,1, \ldots, n)$ are z-transform coefficients.

Referring to Eq. 1 Eq. 4, the relationship at time $t$ between E-A/C cooling load $Q_{L}(t)$ and compartment heat $Q(t)$ can be expressed as below.

$$
Q_{L}(t)=\sum_{j=0}^{n} v_{j} Q(t-j)-\sum_{j=1}^{n} w_{j} Q_{L}(t-j)
$$

$Q(t-j)=$ compartment heat at time. $Q_{L}(t-j)=\mathrm{E}-$ $\mathrm{A} / \mathrm{C}$ cooling load at time $t-j$.

Since Eq. 5 converges quickly, it is sufficient to take three coefficients when applying.

$$
Q_{L}(t)=v_{0} Q(t)+v_{1} Q(t-1)-w_{1} Q_{L}(t-1)
$$

Referring to Eq. 1 Eq. 6, we can conclude the relationship between $\mathrm{E}-\mathrm{A} / \mathrm{C}$ cooling load and bus driving conditions.

$$
Q_{L}(t)=f_{L}\left(T_{i}(t), n(t), T_{o}(t)\right)
$$

$$
f_{L}=\text { Functional relationship. }
$$

\subsection{Temperature in bus compartment}

Referring to related design standard ${ }^{[7]}$, the temperature in long-term stay area in summer can be set from $24^{\circ} \mathrm{C}$ to $28^{\circ} \mathrm{C}^{[6]}$. For electric bus, it is common to set compartment temperature at $25^{\circ} \mathrm{C}$ even lower. If the temperature response process in bus compartment is regarded as a pure delay term, the temperature in compartment can be expressed as below.

$$
T_{i}(t)=T_{s}(t)+\left(T_{o}(t)-T_{s}(t)\right) e^{-\tau / \tau_{0}}
$$

$\tau_{0} \quad=$ Constant. $\quad T_{i}(t) \quad=$ temperature inside compartment. $T_{s}(t)=$ Target temperature. $\tau=$ Time from setting $T_{s}(t) \cdot T_{o}(t)=$ Outside temperature.

Then, bus compartment heat and E-A/C cooling load at time $t$ can be expressed as below.

$$
\begin{gathered}
Q(t)=\varphi\left(T_{i}(t), n(t), T_{o}(t)\right) \\
Q_{L}(t)=\varphi_{L}\left(T_{i}(t), n(t), T_{o}(t)\right)
\end{gathered}
$$

$\varphi, \varphi_{L}=$ Functional relationship.

While E-A/C is under working, which produces cooling to offset the heat that bus compartment has received so as to sustain the temperature around target temperature, so the changing process of bus compartment temperature can be expressed as below.

$$
\frac{d T_{i}(t)}{d t}=\frac{Q_{L}(t)-Q(t)}{V_{V} \times C_{p} \times \rho}
$$

$V_{V}=$ Bus compartment volume. $\rho=$ Air density.

Referring to Eq. 7 Eq. 11, the changes of bus compartment temperature, the number of passengers and the target temperature can affect the cooling load of E$\mathrm{A} / \mathrm{C}$, so we can do energy-saving by setting reasonable target temperature in bus compartment. There are evidences show that the human comfortable temperature indoor can change with outdoor temperature ${ }^{[8,9]}$, if the difference between interior and exterior compartment temperature is too big, it can do harm to health of passengers. When the number of passengers is small, bus compartment temperature is desired to be raised for improving energy efficiency of E-A/C. Once the bus is working under rapid acceleration and climbing conditions, and electronic accelerator pedal stroke reaches 0.9 , the speed of $\mathrm{E}-\mathrm{A} / \mathrm{C}$ compressor is desired to be turned to the lowest for avoiding excessive discharge current of battery. Once battery SOC value is less than 0.2 , E-A/C can be turned off. Now, temperature in bus compartment can be expressed as below.

$T_{i}(t)= \begin{cases}T_{s}(t)+\left(T_{o}(t)-T_{s}(t)\right) e^{-\tau / \tau_{0}} & \left(24<T_{s}(t)=a+b \cdot T_{o}(t)<28\right) \\ T_{s, \text { max }}+\left(T_{o}(t)-T_{s, \text { max }}\right) e^{-\tau / \tau_{0}} & \left(n(t)<0.2 n_{\max }\right)\end{cases}$

$T_{s, \mathrm{max}}=$ Upper limit value determined by the design specification. $a, b=$ Parameters for experimental data for different climatic regions.

Referring to the principle of E-A/C, the shaft power of $\mathrm{E}-\mathrm{A} / \mathrm{C}$ compressor is determined by cooling load, the power consumed by E-A/C can be expressed as below.

$$
\begin{gathered}
P_{A C}(t)=\varphi_{A}\left(Q_{L}(t)\right)=\varphi_{a}\left(T_{i}(t), n(t), T_{o}(t), n(t), S O C(t)\right) \quad(13) \\
P_{A C}(t)=\text { Power consumed by E-A/C. } \varphi_{A},
\end{gathered}
$$
$\varphi_{a}=$ Functional relationship.

Above all, it is possible to adjust bus compartment temperature dynamically according to the changes of bus driving conditions by setting reasonable target temperature, for making full use of the electric energy of the battery, reducing energy consumption of E-A/C.

\section{Simulation and analysis}

\subsection{E-A/C model and electric bus model}

In order to verify the effectiveness of the proposed control method based on driving conditions, a bus model, including an E-A/C model, is established in AVL Cruise and MATLAB. The main parameters of the bus and E$\mathrm{A} / \mathrm{C}$, as shown in Table 1 and Table 2.

Table1 Main parameters of electric bus

\begin{tabular}{|c|c|}
\hline Item & Value \\
\hline Curb weight $[\mathrm{kg}]$ & 11000 \\
\hline Maximum mass $[\mathrm{kg}]$ & 16500 \\
\hline Windward area $\left[\mathrm{m}^{2}\right]$ & 6.8 \\
\hline
\end{tabular}




\begin{tabular}{|l|l|}
\hline Battery total energy $[\mathrm{kWh}]$ & 112 \\
\hline
\end{tabular}

Table 2 Main parameters of E-A/C

\begin{tabular}{|c|c|}
\hline Item & Value \\
\hline Rated power $[\mathrm{kW}]$ & 9.5 \\
\hline Maximum cooling capacity $[\mathrm{kW}]$ & 37 \\
\hline Operating Voltage $[\mathrm{V}]$ & DC 250 to 820 \\
\hline Temperature adjustment range $\left[{ }^{\circ} \mathrm{C}\right]$ & 15 to 30 \\
\hline
\end{tabular}

Referring to bus body structure and other parameters, the electric bus model is established in AVL Cruise, as shown in Fig. 1.

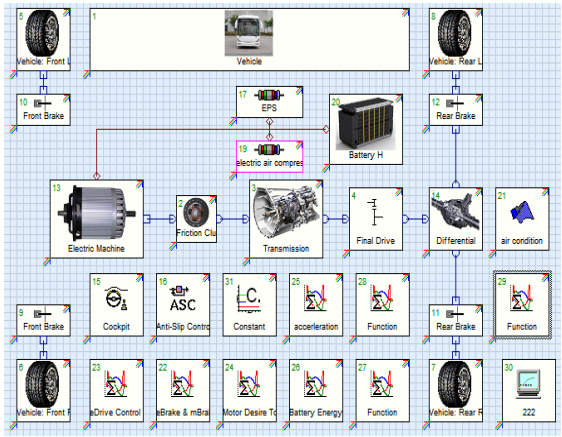

Fig.1 The electric bus model in AVL Cruise

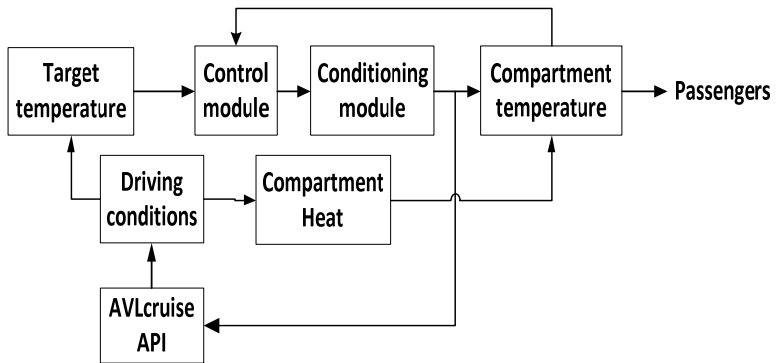

Fig.2 Electric air conditioning model in MATLAB

Referring to other parameters of $\mathrm{E}-\mathrm{A} / \mathrm{C}$, the $\mathrm{E}-\mathrm{A} / \mathrm{C}$ model is established in MATLAB, as shown in Fig. 2. The E-A/C model mainly includes heat calculation module, E-A/C control module, API interface module and temperature calculation module. During simulation, conditioning module can calculate $\mathrm{E}-\mathrm{A} / \mathrm{C}$ power consumption, then do data exchange with bus model in AVL Cruise by API interface, then bus energy consumption and driving range can be calculated in AVL Cruise. E-A/C control module controls the rotation speed and torque of compressor by fuzzy control rules set by the difference between current temperature and target temperature, and the change rate of the difference.

The fuzzy subset of temperature difference is taken as nnegative large, negative small, small, medium, positive\}, the fuzzy subset of the temperature difference change rate is taken as negative large, negative small, small, positive\}, compressor speed and torque are blurred, the subset is taken as \{minimum, small, small, large, large \}, trigonometric function is used to obtain the membership function curve of each of the above parameters. The speed fuzzy domain is $[500,6000] \mathrm{r} / \mathrm{min}$ and the torque fuzzy domain is $[15,35] \mathrm{Nm}$. During simulation, energy consumption of $\mathrm{E}-\mathrm{A} / \mathrm{C}$ is calculated in real time.

\subsection{Simulation and analysis}

Setting experimental conditions before simulation, mainly including urban test cycle (normal road), outside temperature of bus and number of passengers. Among them, the number of passengers is taken as the input of a real bus route, outside temperature $T_{o}(t)$ can be expressed as below.

$$
T_{o}(t)=T_{A o}+T_{A j} \sin \left(\omega_{j} t-\phi_{j}\right)
$$

$T_{A o}=$ Average value of outside temperature. $\omega_{j}$, $\varphi_{j}=$ Parameters of indicating the change of outside temperature. $T_{A j}=$ Temperature fluctuation amplitude.

After simulation, we can get the change of bus compartment temperature when $\mathrm{E}-\mathrm{A} / \mathrm{C}$ is controlled by setting reasonable dynamical target temperature based on driving conditions. As shown in Figure 3.

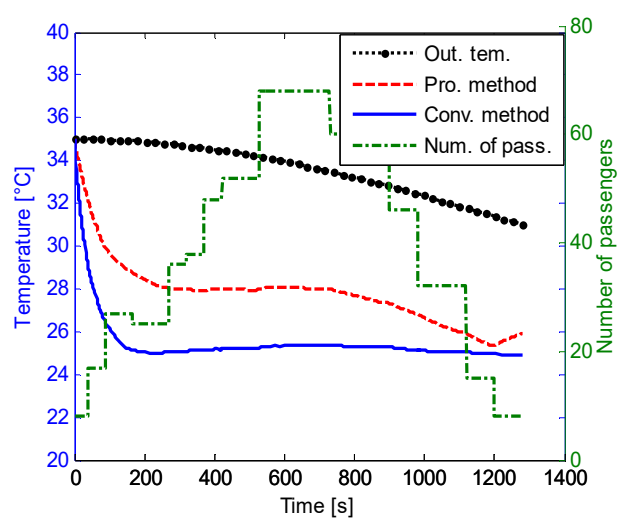

Fig.3 Temperature in bus compartment changes with time

As can be seen from Fig. 3, bus compartment temperature can change with outside temperature and the number of bus passengers by controlling $\mathrm{E}-\mathrm{A} / \mathrm{C}$ according to bus driving conditions, At the beginning, the number of passengers is small, higher target temperature is set for saving energy, and bus compartment temperature can reach set target temperature rapidly. as the number increases, lower target temperature is properly set for improving comfort. Meanwhile, We can get the change of E-A/C energy consumption with time. As shown in Fig. 4.

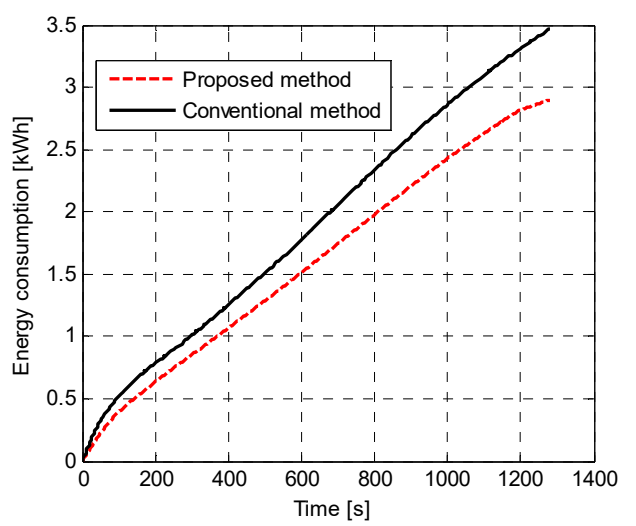

Fig.4 Electric air conditioning energy consumption

As can be seen from Fig. 4, energy consumption of $\mathrm{E}-\mathrm{A} / \mathrm{C}$ in different control methods can be expressed as below. 


$$
\begin{aligned}
E_{1}(t) & =\int P_{A C 1}(t) d t \\
E_{2}(t) & =\int P_{A C 2}(t) d t
\end{aligned}
$$

$E_{1}(t)=\mathrm{E}-\mathrm{A} / \mathrm{C}$ energy consumption of conventional method. $E_{1}(t)=\mathrm{E}-\mathrm{A} / \mathrm{C}$ energy consumption of proposed method in this paper.

The difference of E-/AC energy consumption can be expressed as below.

$$
\begin{aligned}
\Delta E(t) & =E_{1}(t)-E_{2}(t) \\
& =\int\left(P_{A C 1}(t)-P_{A C 2}(t)\right) d t \quad\left(P_{A C 1}(t)-P_{A C 2}(t) \geq 0\right)
\end{aligned}
$$

As time increases, the energy-saving effect under proposed control method will be more remarkable. The comparison of bus driving range and energy consumption under the two control methods, as shown in Table 3.

Table 3 Bus driving range and energy consumption comparison

\begin{tabular}{|c|c|c|c|}
\hline \multirow{2}{*}{ Item } & \multicolumn{3}{|c|}{ Value } \\
\cline { 2 - 4 } & $\begin{array}{c}\text { Proposed } \\
\text { method }\end{array}$ & $\begin{array}{c}\text { Conventional } \\
\text { method }\end{array}$ & Change \\
\hline $\begin{array}{c}\text { Bus energy } \\
\text { consumption } \\
{[\mathrm{kWh} / 100 \mathrm{~km}]}\end{array}$ & 143.94 & 152.71 & $-5.74 \%$ \\
\hline $\begin{array}{c}\text { Driving } \\
\text { range[km] }\end{array}$ & 83.37 & 78.58 & $6.09 \%$ \\
\hline $\begin{array}{c}\text { E-A/C energy } \\
\text { consumption } \\
{[\mathrm{kWh} / 100 \mathrm{~km}]}\end{array}$ & 38.31 & 47.08 & $-18.63 \%$ \\
\hline
\end{tabular}

As can be seen from Table 3, compared with conventional E-A/C control method, E-/AC energy consumption in proposed method decreases by $18.63 \%$, electric bus energy consumption per 100 kilometers decreases by $5.74 \%$, driving range increases by $6.09 \%$. The results also show that E-A/C energy consumption has significant impact on bus performance, E-A/C energy consumption account for $30.83 \%$ and $26.62 \%$ in two control methods.

\section{Summary}

Aiming at the problem of large energy consumption of $\mathrm{E}-\mathrm{A} / \mathrm{C}$, the factors that affect $\mathrm{E}-\mathrm{A} / \mathrm{C}$ cooling load are studied and analyzed in this paper, then a new E-A/C control method based bus driving conditions is proposed, an E-A/C model and electric bus model are established for verifying the effectiveness of the proposed method.

The changes of bus compartment temperature, energy consumption of $\mathrm{E}-\mathrm{A} / \mathrm{C}$ and bus performance with time are compared under conventional method and proposed method. The results show that E-A/C energy consumption can be significantly reduced by dynamically adjusting bus compartment temperature based on driving conditions, and the driving range and economy of bus can be effectively improved. Meanwhile, the usage of E-A/C can greatly reduce the economy and driving range of electric bus.

\section{Acknowledgement}

This research was financially supported by the Youth Science and Technology Talent Development Project of Guizhou Province (Qian Jiao He KY Zi [2017]230).

\section{References}

1. Hong-wen HE. The Principle and Structure of Electric Vehicle (Mechanical Industry Press, Beijing, 2012)

2. Hai-tao MIN, Yun-bo CAO, et al. Journal of Jilin University: Engineering and Technology Edition, S1, 53 (2009)

3. Pethaiah, Sethu Sundar, Alison Subiantoro, et al. Symposium on Energy Technology/Battery-Joint General Session-223rd Meeting (Electrochemical Society, Toronto, 2013)

4. Chien-Chin CHIU, Nan-Chyuan TSAI, et al. Energy, 66, 342 (2014)

5. Shi-xun LU, Wan-feng YANG. Air conditioning technology and engineering applications (Shanghai Jiaotong University Press, Shanghai, 2010)

6. GB 50019-2012. Code for Design of Hating Ventalation and Air Conditioning (China Building Industry Press, Beijing, 2003)

7. Yan MAO. Study on Climate Adaptability of Human Thermal Comfort (Xi'an University of Architecture and Technology, Xi'an, 2006)

8. Richard J.de DEAR; Gall SB. ASHRAE Trans, 104, 145 (1998)

9. Qing-hong PENG, Qun-gui DU. Machinery Design \& Manufacture, 3, 35 (2015) 